Atmos. Chem. Phys., 13, 9789-9800, 2013

www.atmos-chem-phys.net/13/9789/2013/

doi:10.5194/acp-13-9789-2013

(c) Author(s) 2013. CC Attribution 3.0 License.

\title{
Photochemical chlorine and bromine activation from artificial saline snow
}

\author{
S. N. Wren, D. J. Donaldson, and J. P. D. Abbatt \\ Department of Chemistry, University of Toronto, 80 St. George St., Toronto, ON M5S 3H6, Canada
}

Correspondence to: D. J. Donaldson (jdonalds@chem.utoronto.ca) and J. P. D. Abbatt (jabbatt@chem.utoronto.ca)

Received: 25 April 2013 - Published in Atmos. Chem. Phys. Discuss.: 30 May 2013

Revised: 8 August 2013 - Accepted: 22 August 2013 - Published: 7 October 2013

\begin{abstract}
The activation of reactive halogen species - particularly $\mathrm{Cl}_{2}$ - from sea ice and snow surfaces is not well understood. In this study, we used a photochemical snow reactor coupled to a chemical ionization mass spectrometer to investigate the production of $\mathrm{Br}_{2}, \mathrm{BrCl}$ and $\mathrm{Cl}_{2}$ from $\mathrm{NaCl} / \mathrm{NaBr}$ doped artificial snow samples. At temperatures above the $\mathrm{NaCl}$-water eutectic, illumination of samples $(\lambda>310 \mathrm{~nm})$ in the presence of gas phase $\mathrm{O}_{3}$ led to the accelerated release of $\mathrm{Br}_{2}, \mathrm{BrCl}$ and the release of $\mathrm{Cl}_{2}$ in a process that was significantly enhanced by acidity, high surface area and additional gas phase $\mathrm{Br}_{2} \cdot \mathrm{Cl}_{2}$ production was only observed when both light and ozone were present. The total halogen release depended on [ozone] and pre-freezing $[\mathrm{NaCl}]$. Our observations support a "halogen explosion" mechanism occurring within the snowpack, which is initiated by heterogeneous oxidation and propagated by $\mathrm{Br}_{2}$ or $\mathrm{BrCl}$ photolysis and by recycling of $\mathrm{HOBr}$ and $\mathrm{HOCl}$ into the snowpack. Our study implicates this important role of active chemistry occurring within the interstitial air of aged (i.e. acidic) snow for halogen activation at polar sunrise.
\end{abstract}

\section{Introduction}

In the polar regions, heterogeneous reactions occurring on various frozen sea ice surfaces are thought to be responsible for the activation and release of reactive halogen species (particularly $\mathrm{Br}_{2}$, BrO and $\mathrm{HOBr}$ ) (Simpson et al., 2007b and references therein). At polar sunrise, reactive bromine species readily dissociate to yield $\mathrm{Br}$ radicals that can catalytically destroy ozone or participate in other atmospheric oxidation processes, thereby influencing the oxidative capacity of the polar boundary layer. Although a strong role for bromine in both springtime ozone depletion (Simpson et al., 2007b) and mercury oxidation (Steffen et al., 2008) has now been well established, many of the mechanistic details of bromine activation are still lacking, precluding a good understanding of the environmental conditions and sea ice/snow substrates that lead to such events (Abbatt et al., 2012).

Moreover, the role that chlorine plays in these processes is less well known - in part due to a scarcity of reliable field measurements of photolyzable chlorine species (Saiz-Lopez and von Glasow, 2012). Due to the high reactivity of $\mathrm{Cl}$ radicals, elevated chlorine levels are also expected to perturb the chemical composition and oxidative capacity of the troposphere, with their greatest impact likely being on the oxidation of volatile organic compounds (Simpson et al., 2007b).

Laboratory studies have shown that oxidation reactions involving $\mathrm{O}_{3}$ (Oum et al., 1998; Oldridge and Abbatt, 2011; Wren et al., 2010), OH (Sjostedt and Abbatt, 2008) and $\mathrm{HOBr}$ (Huff and Abbatt, 2002; Adams et al., 2002; Kirchner et al., 1997) will liberate $\mathrm{Br}_{2}$ (and in some cases $\mathrm{BrCl}$ ) but not $\mathrm{Cl}_{2}$ from frozen halide solutions. Indeed, the dark ozonation of frozen $\mathrm{Br}^{-}$solutions is thought play an important role in forming "seed" $\mathrm{Br}_{2}$. The proposed mechanism is based on known aqueous phase chemistry (see Finlayson-Pitts, 2003 and references therein):

$$
\begin{aligned}
& \mathrm{O}_{3}(\mathrm{~g})+\mathrm{Br}^{-} \leftrightarrow \mathrm{OBr}^{-} \\
& \mathrm{OBr}^{-}+\mathrm{H}^{+} \leftrightarrow \mathrm{HOBr} \\
& \mathrm{HOBr}+\mathrm{Br}^{-}+\mathrm{H}^{+} \rightarrow \mathrm{Br}_{2}+\mathrm{H}_{2} \mathrm{O}
\end{aligned}
$$

When the $\mathrm{Br}^{-} / \mathrm{Cl}^{-}$is low, $\mathrm{HOBr}$ will also oxidize chloride to yield $\mathrm{BrCl}$ (Fickert et al., 1999; Adams et al., 2002):

$\mathrm{HOBr}+\mathrm{Cl}^{-}+\mathrm{H}^{+} \rightarrow \mathrm{BrCl}+\mathrm{H}_{2} \mathrm{O}$ 
$\mathrm{BrCl}$ formed via Reaction (R4) has a lower volatility than $\mathrm{Br}_{2}$ and may undergo further reactions in the condensed phase to yield $\mathrm{Br}_{2}$ (g) (Finlayson-Pitts, 2003). This, together with the faster rate constant for Reaction (R3) relative to Reaction (R4) (Finlayson-Pitts, 2003), leads to the preferential release of $\mathrm{Br}_{2}(\mathrm{~g})$. The analogous dark ozonation of $\mathrm{Cl}^{-}$Reaction (R5) is too slow to be considered an important $\mathrm{Cl}_{2}$ source (Finlayson-Pitts, 2003).

$\mathrm{O}_{3}(\mathrm{~g})+\mathrm{Cl}^{-} \leftrightarrow \mathrm{OCl}^{-}$

Recent field measurements which have revealed higher-thanexpected concentrations of molecular chlorine in the polar boundary layer (up to 400 pptv) (Impey et al., 1997; Stephens et al., 2012; Liao et al., 2013) have therefore left researchers searching for a missing chlorine source. Field measurements by Impey et al. (1997) during the Polar Sunrise Experiment show that $\mathrm{Cl}_{2}$ follows a diurnal cycle with a daytime maximum, indicating a photochemical source. Recent measurements of $\mathrm{Cl}_{2}$ at Barrow, AK (USA), suggest that $\mathrm{Cl}_{2}$ is correlated with both ozone and actinic flux (Liao et al., 2013). These observations motivated the current study, which seeks to investigate whether a reaction involving both light and ozone is responsible for activating chlorine from frozen sea ice/snow surfaces.

The majority of laboratory studies of halogen activation from frozen $\mathrm{NaCl} / \mathrm{NaBr}$ solutions have been performed using low surface area ice samples; studies performed using high surface area snow samples are completely lacking. Furthermore, motivated by the importance of stratospheric halogen activation, much of the research has been carried out at very low temperatures. There is a need for more studies to be performed at the milder temperatures that are commonly found in the Arctic spring. Not only are such temperatures more relevant for the polar boundary layer, they represent a regime within which sea ice substrates will remain partially liquid and hence the chemistry may be quite different (Koop et al., 2000). Finally, no laboratory studies have been performed in the presence of light, which has the potential to drive $\mathrm{HO}_{\mathrm{x}}\left(=\mathrm{OH}+\mathrm{HO}_{2}\right)$ chemistry and halogen radical reactions within the snowpack. Very recently, a field study using natural snow and ice substrates demonstrated the importance of light-driven snowpack chemistry to halogen activation (Pratt et al., 2013). The specific goal of our study was to determine whether a photochemical pathway exists for halogen activation from artificial snow in the presence of gas phase $\mathrm{O}_{3}$ and radiation at actinic wavelengths. Significant to this study is the choice of high surface area samples and temperatures spanning the $\mathrm{NaCl}$-water eutectic of 252 $\mathrm{K}$. Unlike many previous studies, we chose to focus particularly on chlorine activation by using snow with a low bromide content. In controlled laboratory experiments, we studied the impact of environmental factors such as temperature, acidity, salt content, $\mathrm{Br}^{-} / \mathrm{Cl}^{-}$ratio, snow surface area and $\left[\mathrm{O}_{3}\right]$ on the observed dihalogen release.
Table 1. Parameters used in the experiments. The BASE scenario conditions are shown in bold text.

\begin{tabular}{|c|c|}
\hline Parameter & Range \\
\hline Illumination & $\begin{array}{l}310 \mathrm{~nm} \text { long-pass filter, } 360 \mathrm{~nm} \text { long-pass fil- } \\
\text { ter (w/ Xe lamp) }\end{array}$ \\
\hline [Ozone] & $2.7 \times 10^{13}-\mathbf{1 . 3} \times \mathbf{1 0} \mathbf{1 0}^{\mathbf{1 5}}$ molecules $\mathrm{cm}^{-3}$ \\
\hline Snowpack T & $(248,252,254,257,263) \pm 1 \mathrm{~K}$ \\
\hline Pre-freezing $[\mathrm{NaCl}]$ & $0.1,0.5,1.0 \mathrm{M}$ \\
\hline $\mathrm{Br}^{-}$in $\mathrm{NaCl}(\mathrm{s})$ & $\begin{array}{l}<0.01 \text { wt } \% \text { (reagent grade), }<0.001 \mathrm{wt} \% \\
\text { (high purity) }\end{array}$ \\
\hline Pre-freezing $\mathrm{pH}$ & 2.3, 4.3, ambient $(\sim 5.9)$ \\
\hline Size fraction & fine, coarse \\
\hline
\end{tabular}

\section{Materials and methods}

\subsection{Experimental apparatus}

The overall experimental setup is shown in Fig. 1 and the experimental parameters and ranges are given in Table 1. Compressed air (Linde, Air Grade 0.1) served as the carrier gas for these experiments. The relative humidity (RH) of the carrier gas was controlled by diverting the bulk of the flow $(190 \mathrm{sccm})$ through a $\sim 45 \mathrm{~cm}$ long, double-jacketed Pyrex glass flow tube that was partially filled with crushed ice. Air passing through the RH conditioning flow tube was saturated with the water vapour pressure over ice at the experimental temperature, thereby minimizing the potential for evaporation or condensation of water from or to the snow sample. Ozone $\left(\mathrm{O}_{3}\right)$ was generated by passing the remaining flow of dry compressed air (20 sccm) by a Hg Pen-Ray lamp. The ozone-rich air then passed through a $10 \mathrm{~cm}$ path-length quartz cell where the ozone concentration was determined from the attenuated output of a second Hg Pen-Ray lamp $\left(\lambda_{\max }=254 \mathrm{~nm}\right)$. The ozone-rich air reconnected with the RH-rich air downstream of the RH conditioning flow tube.

The snow reaction chamber consists of a double-jacketed Pyrex glass vessel. Artificial snow was "poured" into the opening at the top of the reaction chamber to create a cylindrical snow sample $\sim 7 \mathrm{~cm}$ tall and $\sim 4 \mathrm{~cm}$ in diameter. Gases entered at the base of the snow sample through a $6.35 \mathrm{~mm}$ diameter inlet located on the side of the reaction chamber and were vented through a side-arm located just above the top of the snow sample. The reaction chamber was held at atmospheric pressure and a critical orifice controlled the flow of gases into the ion-molecule reaction region of the chemical ionization mass spectrometer (CIMS).

The samples were illuminated through a window at the top of the reaction chamber by the output of a $1 \mathrm{~kW}$ Xenon (Xe) arc lamp. A $\sim 20 \mathrm{~cm}$ path length water filter was placed between the arc lamp and the sample to remove infrared (IR) radiation to prevent over-heating of the sample, and a mirror directed the light onto the sample. In the majority of experiments a $310 \mathrm{~nm}$ long-pass filter (10\% transmission at $310 \mathrm{~nm}$, measured using a commercial UV-VIS 


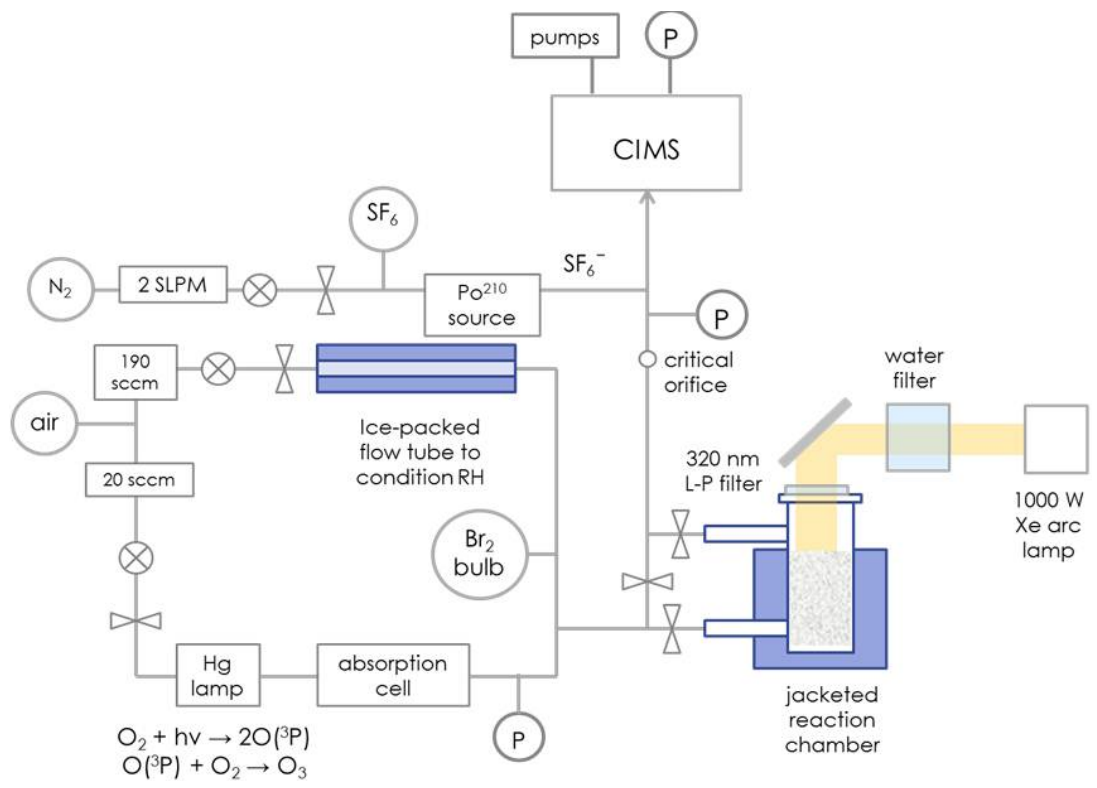

Fig. 1. Schematic of experimental apparatus.

spectrometer) was also placed over the quartz glass window. In some experiments, the $310 \mathrm{~nm}$ filter was replaced by a $360 \mathrm{~nm}$ long-pass filter ( $10 \%$ transmission at $360 \mathrm{~nm}$ ). Additional experiments were performed in which $\mathrm{Br}_{2}$ or $\mathrm{Cl}_{2}$ was introduced from a glass bulb manifold through the empty reaction chamber. Illumination did not lead to a measurable decrease in the $\mathrm{Br}_{2}$ or $\mathrm{Cl}_{2}$ signals in the absence of ozone for (a) the full spectral output of the Xe lamp with water filter and (b) the same as (a) but with a $310 \mathrm{~nm}$ or $360 \mathrm{~nm}$ longpass filter.

The temperature of the reaction chamber and the $\mathrm{RH}$ conditioning flow tube were controlled by a Neslab chiller. The temperature in the reaction chamber was occasionally checked using a thermocouple and was typically $\sim 5 \mathrm{~K}$ warmer than the chiller set point temperature. Reported temperature refers to the temperature of the snow within the reaction chamber.

\subsection{Chemical ionization mass spectrometer}

Gases were detected using a custom-built chemical ionization mass spectrometer (CIMS). The instrument, which is described in greater detail in Thornberry and Abbatt (2004), consists of two differentially pumped regions: the ion molecule region (IMR) and the multiplier chamber (MC). During operation, the pressures are 2.5 Torr and $2.5 \times 10^{-6}$ Torr in the IMR and the MC respectively. The CIMS control box (Merlin QMS Controller) is interfaced to a PC operating using Merlin software from EXTREL (ABB Process Analytics, Inc.).

A trace flow of $\mathrm{SF}_{6}$ (BOC, Grade 3.0), seeded in a 2 slpm dry $\mathrm{N}_{2}$ flow (Linde, $\mathrm{N}_{2}$ liquid Grade 4.8 ) was passed over a ${ }^{210} \mathrm{Po}$ ion source to produce the reagent ion, $\mathrm{SF}_{6}^{-}$, via electron attachment. A $-112 \mathrm{~V}$ applied to the sheath surrounding the ion source helped direct the reagent ions into the IMR. Gas phase species produced by the experiment $\left(\mathrm{O}_{3}, \mathrm{Cl}_{2}, \mathrm{BrCl}\right.$ and $\mathrm{Br}_{2}$ ) were swept into the IMR by the carrier gas flow; chargetransfer reactions with the reagent gas occurred in the IMR:

$\mathrm{X}+\mathrm{SF}_{6}^{-} \rightarrow \mathrm{X}^{-}+\mathrm{SF}_{6}$

Thus, $\mathrm{O}_{3}, \mathrm{Cl}_{2}, \mathrm{BrCl}$ and $\mathrm{Br}_{2}$ were detected at $\mathrm{m} / z$ 48, 70, 114 and 160 respectively. A scan time of $2 \mathrm{~s}$ was used. Ions entered the mass spectrometer through a pinhole which was biased to $-14 \mathrm{~V}$.

$\mathrm{SF}_{6}^{-}$was chosen as the reagent ion because it can be used to simultaneously measure both $\mathrm{O}_{3}$ and dihalogens. The reaction of $\mathrm{SF}_{6}^{-}$with $\mathrm{O}_{3}$ is very fast, near the collision rate (Huey et al., 1995). The reactions of $\mathrm{SF}_{6}^{-}$with $\mathrm{Br}_{2}$ and $\mathrm{BrCl}$ are also fast, but the reaction with $\mathrm{Cl}_{2}$ is slower (Huey et al., 1995). Although the reaction between $\mathrm{SF}_{6}^{-}$and water vapour is fairly slow, high mixing ratios of water vapour often preclude the use of $\mathrm{SF}_{6}^{-}$as a reagent ion. However, at the cold temperatures used in these experiments and with the pressure drop to 2.5 Torr in the IMR, the water vapour pressure was low enough that the reagent ion signal remained sufficiently high.

\subsection{Calibration}

Calibrations for $\mathrm{Cl}_{2}$ and $\mathrm{Br}_{2}$ were performed routinely. Calibrations were performed in the absence of ozone with the reaction chamber bypassed. A small flow of either $\mathrm{Cl}_{2}$ or $\mathrm{Br}_{2}$ was released from a fixed-volume manifold to the main carrier gas flow (downstream of the RH conditioning flow tube, 
as indicated in Fig. 1) and the pressure drop in the manifold as a function of time was converted to the equivalent concentration of either $\mathrm{Br}_{2}$ or $\mathrm{Cl}_{2}$ in molecules $\mathrm{cm}^{-3}$.

The $\mathrm{Cl}_{2}$ calibration bulb was prepared by delivering pure $\mathrm{Cl}_{2}(\mathrm{~g})$ (Matheson) to an evacuated glass bulb. The $\mathrm{Cl}_{2}$ in the bulb was then diluted with dry $\mathrm{N}_{2}$ to a final mixing ratio on the order of $10^{-4}$. The measured bulb pressures at the various dilution stages were used to determine the final mixing ratio, assuming ideal gas behaviour. $\mathrm{The} \mathrm{Br}_{2}$ calibration bulb was prepared by flash-freezing a small volume of liquid $\mathrm{Br}_{2}$ in a round-bottom flask, pumping off the remaining vapour, then delivering $\mathrm{Br}_{2}(\mathrm{~g})$ from the round-bottom flask into an evacuated glass bulb after warming the sample. The $\mathrm{Br}_{2}$ in the bulb was then diluted with dry $\mathrm{N}_{2}$ to a final mixing ratio on the order of $10^{-5}$.

The intensity of the reagent ion $\left(\mathrm{SF}_{6}^{-}\right)$varied somewhat from day-to-day. All signals were normalized to the simultaneously measured $\mathrm{SF}_{6}^{-}$signal. During $\mathrm{Cl}_{2}$ calibration, peaks at $\mathrm{m} / \mathrm{z} 70,72$ and 74 respectively corresponding to ${ }^{35} \mathrm{Cl}^{35} \mathrm{Cl}^{-},{ }^{35} \mathrm{Cl}^{37} \mathrm{Cl}^{-}$and ${ }^{37} \mathrm{Cl}^{37} \mathrm{Cl}^{-}$were measured with the expected isotopic distribution. Similarly, during $\mathrm{Br}_{2}$ calibration, peaks at $\mathrm{m} / \mathrm{z}, 158,160$ and 162 respectively corresponding to ${ }^{79} \mathrm{Br}^{79} \mathrm{Br}^{-},{ }^{79} \mathrm{Br}^{81} \mathrm{Br}^{-}$and ${ }^{81} \mathrm{Br}^{81} \mathrm{Br}^{-}$were measured with the expected distribution. Calibrations were not performed for $\mathrm{BrCl}$, but we assume that the CIMS is equally sensitive to $\mathrm{BrCl}$ as it is to $\mathrm{Br}_{2}$ (Abbatt et al., 2010). This assumption is based on their similar gas-phase electron affinities and their fast, collision-rate limited reaction with $\mathrm{SF}_{6}$ (Huey et al., 1995).

The gas flow during calibration led to a CIMS signal in counts per second (cps) from which we determined sensitivity. Typically, the $\mathrm{SF}_{6}^{-}$signal was between $(6-8) \times 10^{4} \mathrm{cps}$ for the ion source. In all cases we normalized the measured ion signals to the $\mathrm{SF}_{6}^{-}$reagent ion signal, which resulted in a unit-less intensity. For $\mathrm{Br}_{2}$ and $\mathrm{BrCl}$ the normalized sensitivity was $1.7 \times 10^{-16}$ per (molecule $\mathrm{cm}^{-3}$ ) and for $\mathrm{Cl}_{2}$ it was $5.8 \times 10^{-17}$ per (molecule $\mathrm{cm}^{-3}$ ). Using these calibrated sensitivities, we determined the concentration of dihalogens being released from the snow (molecules $\mathrm{cm}^{3}$ ).

The limits of detection were determined from the signal-to-noise $(\mathrm{S} / \mathrm{N})$ ratio of the background signal during calibration. The noise was taken as the standard deviation of the background signal, measured for one minute ( 30 scans). For our operating conditions, our detection limits were $(2-3) \times 10^{11}$ molecules $\mathrm{cm}^{-3}$ for $\mathrm{Br}_{2},(1-2) \times 10^{11}$ molecules $\mathrm{cm}^{-3}$ for $\mathrm{BrCl}$ and $(3-$ 5) $\times 10^{11}$ molecules $\mathrm{cm}^{-3}$ for $\mathrm{Cl}_{2}$.

\subsection{Snow preparation}

Artificial snow was prepared from a saline solution of $\mathrm{NaCl}(\mathrm{s})$ in $18 \mathrm{M} \Omega \mathrm{cm}$ deionized water. The molar chloride to bromide ratio $\left(\mathrm{Cl}^{-}: \mathrm{Br}^{-}\right)$was varied by using different purities of $\mathrm{NaCl}(\mathrm{s})$; here we used reagent grade $\mathrm{NaCl}(\mathrm{s})$ (ACP Chemicals, $0.01 \%$ bromide impurity by weight) and

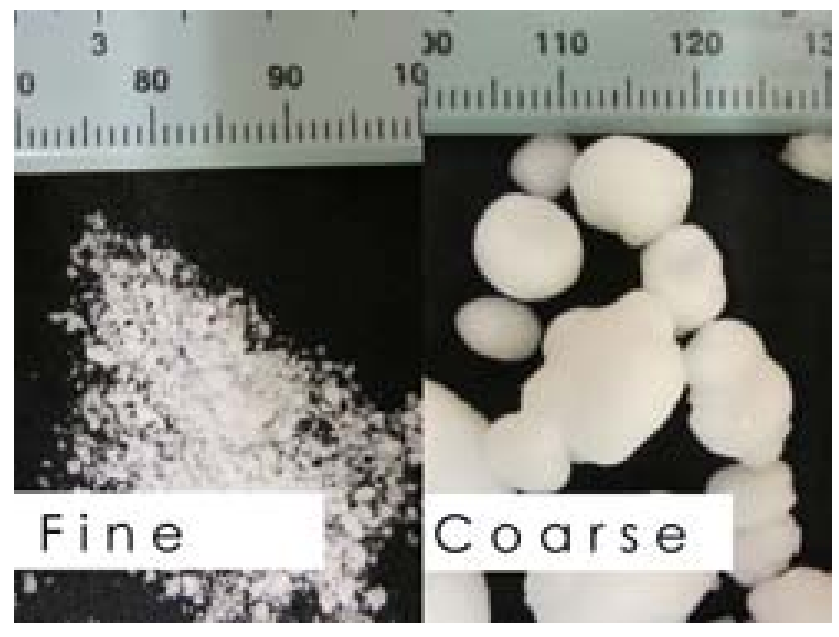

Fig. 2. Photographs of the artificial snow samples taken immediately after preparation.

high purity $\mathrm{NaCl}(\mathrm{s})$ (Fluka TraceSELECT®, $<0.001 \%$ bromide impurity by weight). Note that these salts possess molar $\mathrm{Cl}^{-}: \mathrm{Br}^{-}$ratios that are much higher that the molar seawater $\mathrm{Cl}^{-}: \mathrm{Br}^{-}$ratio of $\sim 650$. The pre-freezing $[\mathrm{NaCl}(\mathrm{aq})]$ was $0.5 \mathrm{M}$ for the majority of these experiments (and was varied between 0.1 and $1.0 \mathrm{M}$ for select experiments). Initial solution $\mathrm{pH}$ was measured using a commercial $\mathrm{pH}$ electrode and adjusted using dilute $\mathrm{H}_{2} \mathrm{SO}_{4}$ (aq) as needed. The pre-freezing $\mathrm{pH}$ was $\sim 2.3$ for the majority of experiments. Unadjusted samples had an ambient $\mathrm{pH} \sim 5.9$. To prepare the snow, the nozzle of a mister bottle was used to disperse the saline solution into fine droplets which were directed into a dewar of liquid $\mathrm{N}_{2}$. The contents of the dewar were then separated using a mesh sieve (hole diameter roughly $1 \mathrm{~mm}$ ). The ice particles (i.e. the snow grains) captured by the sieve were mostly nonspherical (probably due to coagulation of individual droplets) and were estimated to be $\sim 0.5 \mathrm{~mm}$ in diameter. The ice particles that fell through the sieve were very fine and uniform to the eye (appearing as a fine powder), with an estimated diameter $<0.5 \mathrm{~mm}$ (see Fig. 2, left panel). This fine mode fraction was used for the majority of the experiments. All prepared snow was stored in amber glass jars in a freezer at $245 \mathrm{~K}$ for at least 1 day before use to allow the ice particles time to anneal. Coarse mode ice particles were prepared for some experiments by dropping saline solution directly into the liquid $\mathrm{N}_{2}$ using a glass pipette. The resultant ice spheres were very roughly spherical and had a relatively wide size distribution (see Fig. 2, right panel). The mass of snow used was roughly $\sim 40 \mathrm{~g}$ for the fine mode samples and $\sim 50 \mathrm{~g}$ for the coarse mode samples. The snow samples filled a volume in the reaction chamber of $\sim 80 \mathrm{~cm}^{3}$. 

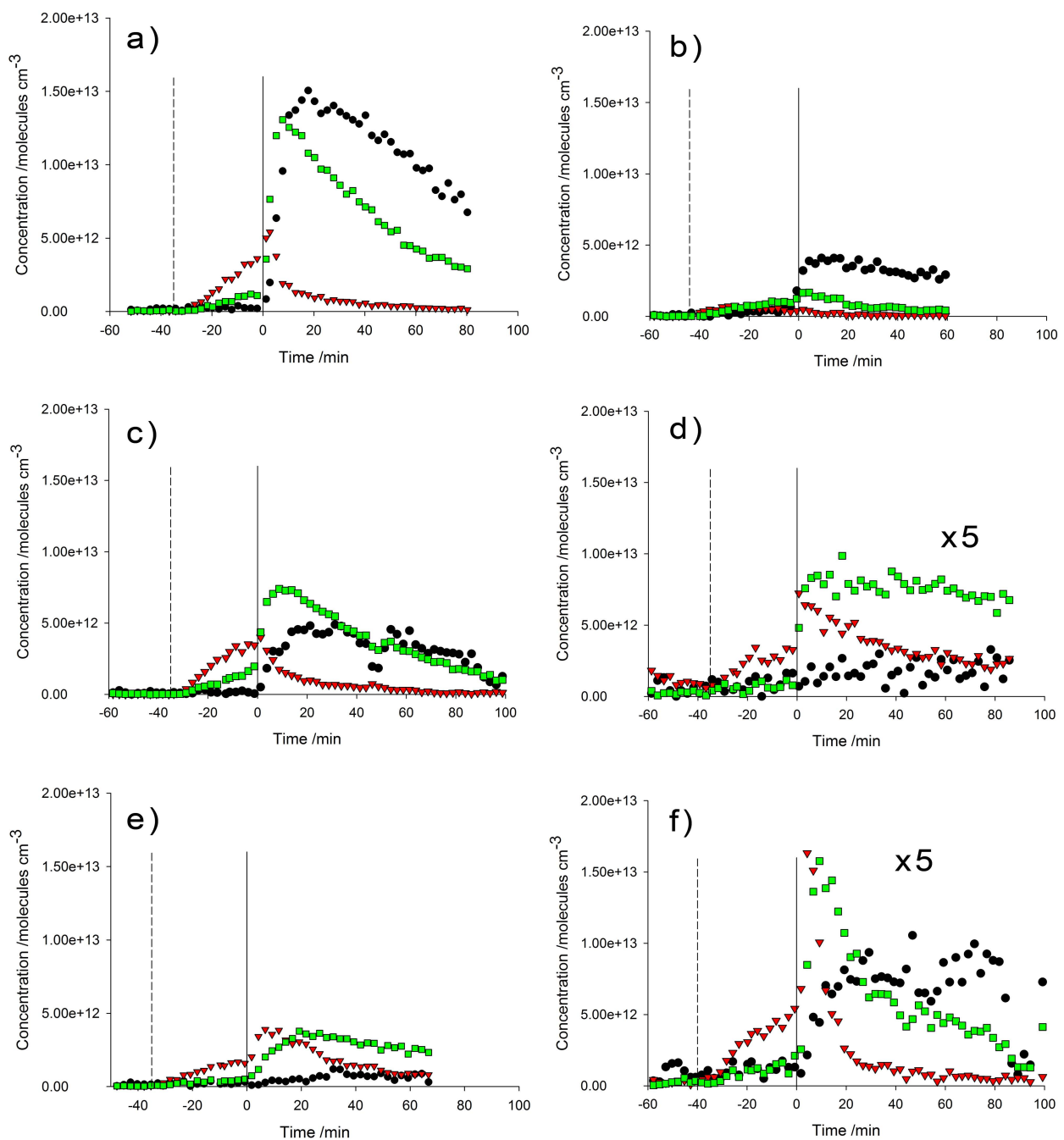

Fig. 3. Time evolution of the dihalogen concentrations during a typical experiment: $\mathrm{Br}_{2}$ (red triangles), $\mathrm{Cl}_{2}$ (black circles) and $\mathrm{BrCl}$ (green squares). Each point represents the average of a $2.5 \mathrm{~min}$ time bin ( 77 data points). The dashed line indicates the time at which the ozone generator was turned on and the solid line $(t=0)$ indicates the time at which the samples were illuminated. (a) BASE scenario conditions as in Table 1; BASE scenario conditions except with (b) high purity $\mathrm{NaCl}(\mathrm{s})\left(\mathrm{Br}^{-}<0.001 \mathrm{wt} \%\right.$ ) to prepare solution; (c) $360 \mathrm{~nm}$ long-pass filter; (d) coarse mode snow, scaled up by a factor of 5; (e) pre-freezing $\mathrm{pH}=4.3$; (f) snowpack $\mathrm{T}=252 \pm 1 \mathrm{~K}$, scaled up by a factor of 5 .

\subsection{Snow characterization}

To ensure that the artificial snow samples retained the same bulk composition as their initial solutions, some of the snow samples were melted and their ionic content was analyzed by ion-chromatography (IC). This was done separately for the coarse and fine fraction to ensure that the method of snow preparation and separation did not result in chemical fractionation. The analysis showed that the chloride concentrations remained unchanged due to freezing (for both the coarse and fine mode fractions). Unfortunately bromide concentrations could not be determined via the IC analysis due to interference from chloride.

\section{Results and discussion}

\subsection{Photochemical chlorine production}

Figure 2a shows results from a typical experiment under conditions that define the "BASE" scenario (which are shown in bold text in Table 1). Figure 3b-f demonstrate the effects of varying one parameter at a time from the BASE scenario. All the figures have the same vertical and horizontal scaling for ease of comparison and in all cases $\mathrm{Cl}_{2}$ is shown as black circles, $\mathrm{Br}_{2}$ as red triangles, and $\mathrm{BrCl}$ as green squares. To aid the interpretation of our results, we occasionally refer to the contribution of a given dihalogen to the total dihalogen sum $\left[\mathrm{Cl}_{2}+\mathrm{Br}_{2}+\mathrm{BrCl}\right]$, henceforward the " $\mathrm{Cl}_{2}$ fraction", " $\mathrm{Br}_{2}$ fraction" and " $\mathrm{BrCl}$ fraction". 
We observe that the dark exposure to ozone liberates $\mathrm{Br}_{2}$ and in some cases $\mathrm{BrCl}$ from the snow (Fig. 3). Prior to illumination, $\left[\mathrm{Br}_{2}\right]$ is greater than $[\mathrm{BrCl}]$, although the contribution of $\left[\mathrm{Br}_{2}\right]$ to the total halogen release $\left(\left[\mathrm{Br}_{2}\right]\right.$ $\left.+[\mathrm{BrCl}]+\left[\mathrm{Cl}_{2}\right]\right)$ decreases slightly with time due to the slow depletion of snow bromide. Over the course of a typical BASE scenario experiment, we estimate that $10-15 \%$ of the total bromide content may react. As mentioned, the dark ozonation of frozen $\mathrm{NaCl} / \mathrm{NaBr}$ solutions has been the subject of previous laboratory studies (Oum et al., 1998; Oldridge and Abbatt, 2011; Wren et al., 2010). These studies (Oldridge and Abbatt, 2011) suggest that the reaction proceeds in a liquid brine layer via a mechanism (Reactions R1R4) that is similar to that occurring on/in the aqueous phase. The dark production of $\mathrm{Br}_{2}$ and $\mathrm{BrCl}$ that we observe here is consistent with those studies.

Under all conditions studied here (i.e. shown in Fig. 3af), illumination of the snow sample (at $t=0$ ) leads to a rapid increase in the concentration of all three dihalogens with the rate of increase most rapid for $\mathrm{Br}_{2}$, slower for $\mathrm{BrCl}$, and followed by $\mathrm{Cl}_{2}$. No halogen production was observed when snow samples were illuminated in the absence of ozone. $\mathrm{Cl}_{2}$ production (above the limits of detection) was only observed when both light and ozone were present.

The focus of this study is the accelerated halogen activation (particularly the $\mathrm{Cl}_{2}$ activation) we observe when the halide-doped snow is exposed to ozone and light. In the following, we show that our observations support a snowpack "halogen explosion" - a chemical mechanism that is initiated by the photolysis of $\mathrm{Br}_{2}$ or $\mathrm{BrCl}$ (formed via the dark ozonolysis of bromide) and perpetuated by the recycling of $\mathrm{HOBr}$ or $\mathrm{HOCl}$ back into the snowpack.

$\mathrm{X}_{2}+h v \rightarrow \mathrm{X}+\mathrm{X}$

$\mathrm{X}+\mathrm{O}_{3} \rightarrow \mathrm{XO}+\mathrm{O}_{2}$

$\mathrm{XO}+\mathrm{HO}_{2} \rightarrow \mathrm{HO}_{\mathrm{x}}+\mathrm{O}_{2}$

$\mathrm{HO}_{\mathrm{x}}+h v \rightarrow \mathrm{OH}+\mathrm{X}$

The mechanism shown above (Reactions (R7)-(R10)) has previously been proposed (Fickert et al., 1999; Fan and Jacob, 1992; Vogt et al., 1996; Foster et al., 2001; Simpson et al., 2007b; Abbatt et al., 2012; Tang and McConnell, 1996) to be important for activating bromine in the polar regions. Although laboratory studies have shown that $\mathrm{HOBr}$ will react with chloride or bromide at ice surfaces to give $\mathrm{Br}_{2}$ or $\mathrm{BrCl}$ under certain conditions (Huff and Abbatt, 2002; Adams et al., 2002; Kirchner et al., 1997), the entire "halogen explosion" mechanism has not been directly investigated in controlled laboratory experiments using frozen substrates. Furthermore, this phenomenon has not been pursued as an important mechanism for activating chlorine in the form of $\mathrm{Cl}_{2}$.

$\mathrm{HOBr}$ formed via $\mathrm{R} 9$ can oxidize $\mathrm{Br}^{-}$in the condensed phase, leading to $\mathrm{Br}_{2}$ and $\mathrm{BrCl}$ through Reaction (R3) and subsequent reactions. The $\mathrm{HOBr}$ can also oxidize $\mathrm{Cl}^{-}$directly to give $\mathrm{BrCl}$ at the surface, which in turn can oxi- dize $\mathrm{Br}^{-}$to $\mathrm{Br}_{2}$ (Adams et al., 2002). $\mathrm{Cl}$ radicals formed via the photolysis of $\mathrm{BrCl}$ (or eventually $\mathrm{Cl}_{2}$ ) provide a route for $\mathrm{HOCl}$ formation, and the $\mathrm{HOCl}$ can oxidize $\mathrm{Cl}^{-}$to give $\mathrm{Cl}_{2}$ directly. In our experiments, we believe that $\left[\mathrm{Cl}_{2}\right]$ grows more slowly because oxidation of $\mathrm{Br}^{-}$will always be favoured over $\mathrm{Cl}^{-}$when it is available and because $\mathrm{Cl}_{2}$ formation requires prior $\mathrm{BrCl}$ formation (to provide $\mathrm{Cl}$ radicals via photolysis). Although molecular $\mathrm{Cl}_{2}$ formation always occurs subsequent to $\mathrm{BrCl}$ formation, its observation contemporaneously to $\mathrm{Br}_{2}$ shows that $\mathrm{Br}^{-}$does not need to be exhausted for $\mathrm{Cl}_{2}$ to form. The $\left[\mathrm{Br}_{2}\right]$ and $[\mathrm{BrCl}]$ decrease rapidly once they have reached their respective maxima; this is presumably due to the fact that the snow is prepared from $\mathrm{NaCl}(\mathrm{s})$ containing only a small bromide impurity $(<0.01 \%$ $\mathrm{Br}^{-}$by weight). Hence there is a small and finite amount of $\mathrm{Br}^{-}$that can be liberated from the snow as either $\mathrm{Br}_{2}$ or $\mathrm{BrCl}$.

\subsection{Direct observation of a snowpack halogen explosion}

A direct role for reactive halogen species in the photochemical activation of halogens from the snow was explored in test experiments in which additional $\mathrm{Br}_{2}$ gas was introduced to the reaction chamber via a fixed-volume glass bulb manifold coupled to the main gas flow. Figure $4 \mathrm{a}$ shows $\left[\mathrm{Cl}_{2}\right],\left[\mathrm{Br}_{2}\right]$ and $[\mathrm{BrCl}]$ and Fig. $4 \mathrm{~b}$ shows $\left[\mathrm{O}_{3}\right]$ (expressed as a normalized signal) during such an experiment. The sample had been previously subjected to a typical experiment so that the concentrations of bromine containing products were very low, indicating a significant depletion of available bromide in the snow sample.

Consistent with the "halogen explosion" mechanism, Fig. $4 \mathrm{a}$ and $\mathrm{b}$ show that exposing this "pre-reacted" halidedoped snow to light, ozone and excess $\mathrm{Br}_{2}$ leads to an increase in $[\mathrm{BrCl}]$ and $\left[\mathrm{Cl}_{2}\right]$ (with $[\mathrm{BrCl}]$ increasing more rapidly than $\left[\mathrm{Cl}_{2}\right]$ ) and a simultaneous decrease in $\left[\mathrm{O}_{3}\right]$. Following an induction period as $\mathrm{Br}_{2}$ is introduced from the bulb, its concentration is also anticorrelated to those of $\mathrm{Cl}_{2}$ and $\mathrm{BrCl}$. Production of $\mathrm{BrCl}$ and $\mathrm{Cl}_{2}$ is not observed (or ceases) when either light, ozone or excess $\mathrm{Br}_{2}$ is absent. Note that the $\left[\mathrm{Br}_{2}\right]$ between $\sim 60-80$ min slowly decreases due to the fact that the additional $\mathrm{Br}_{2}$ is being leaked from a glass bulb of decreasing pressure. Figure $4 \mathrm{a}$ illustrates that higher $[\mathrm{BrCl}]$ and $\left[\mathrm{Cl}_{2}\right]$ are observed when higher $\left[\mathrm{Br}_{2}\right]$ is present. Interestingly, in the absence of ozone, blocking and un-blocking the light has no noticeable impact on the dihalogen concentrations. As mentioned in Sect. 2, depletion of $\mathrm{Br}_{2}$ or $\mathrm{Cl}_{2}$ by photolysis alone was not important under our conditions.

\subsection{Influence of snow $\mathrm{Br}^{-} / \mathrm{Cl}^{-}$}

The important role that bromine activation plays in initiating the "bromine explosion" is also shown in experiments in which we reduced the snow $\mathrm{Br}^{-} / \mathrm{Cl}^{-}$ratio by an order of magnitude (through the use of high purity $\mathrm{NaCl}(\mathrm{s})$ ). 

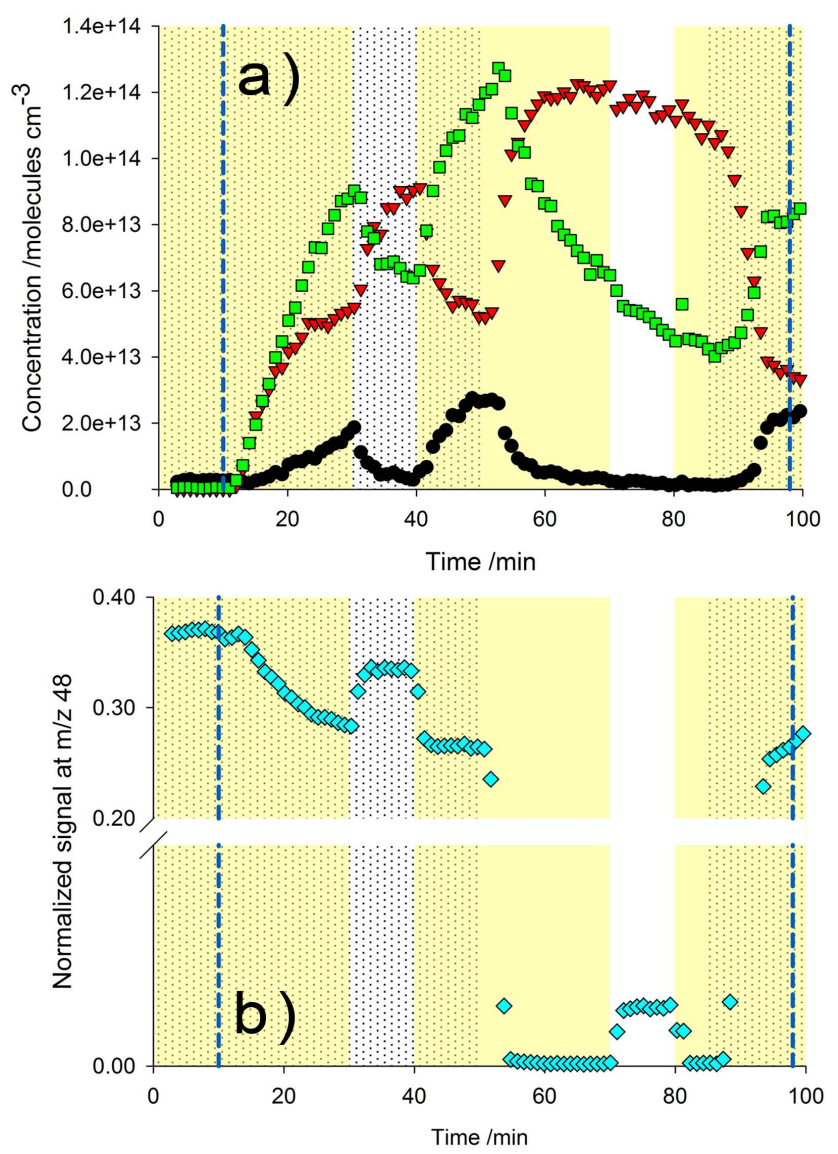

Fig. 4. Time traces of (a) dihalogen concentrations $-\mathrm{Br}_{2}$ (red triangles), $\mathrm{Cl}_{2}$ (black circles) and $\mathrm{BrCl}$ (green squares); and (b) ozone concentrations (light blue diamonds) during an experiment in which an additional flow of $\mathrm{Br}_{2}(\mathrm{~g})$ was delivered to the sample from a glass manifold (in the period of time indicated by the vertical blue dashed lines). The yellow areas indicate time periods during which the sample was illuminated. The dotted areas indicate time periods during which the ozone generator was switched on $\left(\left[\mathrm{O}_{3}\right]\right.$ $\sim 1 \times 10^{14}$ molecules $\mathrm{cm}^{-3}$ ). The experiment was run under BASE scenario conditions except high purity $\mathrm{NaCl}(\mathrm{s})\left(\mathrm{Br}^{-}<0.001 \mathrm{wt} \%\right)$ was used to prepare the solution. Each point represents the average of a 1 min time bin (30 data points).

Figure $3 \mathrm{~b}$ shows that although the $\mathrm{Cl}_{2}$ fraction is clearly enhanced relative to the BASE scenario under these conditions, the overall $\left[\mathrm{Cl}_{2}\right]$ is lower, despite the fact that the prefreezing $\left[\mathrm{Cl}^{-}\right]$is effectively unchanged. The fact that reducing the $\mathrm{Br}^{-} / \mathrm{Cl}^{-}$ratio while keeping pre-freezing $\left[\mathrm{Cl}^{-}\right]$constant leads to a decrease in $\mathrm{Cl}_{2}$ is consistent with a snowpack "halogen explosion" that requires the initial formation of $\mathrm{Br}_{2}$ and $\mathrm{BrCl}$.

\subsection{Wavelength dependence}

Support for a snowpack "halogen explosion" driven by halogen photolysis is also provided by the observed wavelength dependence. Replacing the $310 \mathrm{~nm}$ long-pass filter with a
$360 \mathrm{~nm}$ long-pass filter is expected to reduce the rate constant for dihalogen photolysis $\left(J_{6}\right)$ for $\mathrm{Cl}_{2}\left(\lambda_{\max }=330 \mathrm{~nm}\right)$ much more than for $\mathrm{BrCl}\left(\lambda_{\max }=370 \mathrm{~nm}\right)$; the $\mathrm{J}_{6}$ for $\mathrm{Br}_{2}$ $\left(\lambda_{\max }=420 \mathrm{~nm}\right)$ should be the least effected (Finlayson-Pitts and Pitts, 2000). Indeed, comparison of Fig. 3c with Fig. 3a shows that use of the $360 \mathrm{~nm}$ long-pass filter leads to lower yields of all three dihalogens, which can be attributed to less $\mathrm{HOBr}$ or $\mathrm{HOCl}$ formation via Reactions (R6)-(R8) under these conditions. Furthermore, the slower evolution of the $\mathrm{Cl}_{2}$ fraction under these conditions is consistent with lower yields of $\mathrm{Cl}$ radical due to the fact that the $J_{6}$ for $\mathrm{BrCl}$ and $\mathrm{Cl}_{2}$ photolysis are lowered to a greater extent than the $J_{6}$ for $\mathrm{Br}_{2}$. The fact that we observe photochemical halogen activation under both illumination conditions also allows us to conclude that $\mathrm{OH}(\mathrm{g})$ formed via $\mathrm{O}\left({ }^{1} \mathrm{D}\right)$ from gas phase ozone photolysis is not an important oxidant in our experiments.

\subsection{Surface area dependence}

Central to the "halogen explosion" mechanism is the recycling of gas phase products back into the snow. Hence, halogen activation via this mechanism should be enhanced when a larger surface area is available, and $\mathrm{Cl}_{2}$ production should be most affected since it relies solely on the photochemical pathway (i.e. $\mathrm{Br}_{2}$ and $\mathrm{BrCl}$ can both be formed in the dark). The influence of available surface area was investigated by performing experiments using a coarse mode snow (see Fig. 2, right panel and Fig. 3d), with all other conditions the same as in the BASE scenario. Comparison of Fig. 3a and $\mathrm{d}$ shows that the dihalogen production is indeed suppressed when the available surface area is reduced. In particular, the $\mathrm{Cl}_{2}$ fraction evolves very slowly for the coarse mode experiments; the $\mathrm{BrCl}$ fraction remains high for the duration of the experiment. We note that the larger yields we observe when a greater surface area is present could also support a reaction taking place at the frozen surface. Halide ions are known to have a positive surface affinity (Jungwirth and Tobias, 2006) and thus have the potential to be involved in interfacial reactions (Knipping et al., 2000).

\section{6 $\mathrm{pH}$ dependence}

Dihalogen formation was reduced when the pre-freezing $\mathrm{pH}$ was increased to $\sim 4.3$ (see Fig. 3e). The dark evolution of $\left[\mathrm{Br}_{2}\right]$ was the least affected, while the production of $\left[\mathrm{Cl}_{2}\right]$ upon illumination was dramatically suppressed. At a prefreezing $\mathrm{pH}$ of 5.9, any dihalogen production lay below the detection limits. The strong $\mathrm{pH}$ dependence for $\mathrm{Cl}_{2}$ production may indicate that in the $\mathrm{Cl}^{-}$analog of Reaction (R3), an initial protonation of $\mathrm{HOCl}$ to form $\mathrm{H}_{2} \mathrm{OCl}^{+}$, is the ratelimiting step (as suggested for the aqueous phase by Donaldson et al., 1997). A mechanism involving $\mathrm{HOCl}$ reaction with $\mathrm{H}^{+}$followed by reaction of $\mathrm{H}_{2} \mathrm{OCl}^{+}$with $\mathrm{Cl}^{-}$is also consistent with the lack of temperature dependence on $\mathrm{Cl}_{2}$ yields for temperatures above the eutectic (vide infra). 
A strong acidity dependence has also been reported for the $\mathrm{HOBr}+\mathrm{Br}^{-}$Reaction (R3) in the aqueous phase (Fickert et al., 1999), although the acidity dependence is expected to be weaker than that for chlorine. Although studies of $\mathrm{HOBr}$ reactions with frozen halides substrates have shown that $\mathrm{Br}_{2}$ and $\mathrm{BrCl}$ will form under a wide range of acidities (Huff and Abbatt, 2002; Adams et al., 2002), we note that those studies were carried out at temperatures below the eutectic for which the ice surface should be quite different than in the present experiment and for which we also see little halogen production (see Sect. 3.8).

\section{$3.7 \quad \mathrm{HO}_{\mathrm{x}}$ and $\mathrm{O}_{3}$}

The "halogen explosion" mechanism requires an $\mathrm{HO}_{2}$ source to be present in the snow interstitial air. Snowpacks are now known to be sources of $\mathrm{OH}, \mathrm{HO}_{2}$ and small organics such as HCHO (Domine and Shepson, 2002; Grannas et al., 2007). Indeed, using the same experimental set-up and similar illumination conditions Gao et al. (2012) measured the release of VOCs from natural snow samples collected from urban, rural and remote sites. Although organics were not intentionally introduced to our samples, it is well known that reagent grade salts and laboratory deionized water contain organic impurities (Gao and Abbatt, 2011). It is also possible that gas phase organics or acids present in the room contaminated our samples during preparation (fast-freezing in liquid $\mathrm{N}_{2}$ ). Thus, upon sample illumination, it is possible that active snowpack chemistry leads to $\mathrm{HO}_{\mathrm{x}}$ formation. Additionally, the oxidation of VOCs by $\mathrm{Cl}$ radicals is known to lead to the formation of $\mathrm{HO}_{2}$ and small aldehydes (i.e. $\mathrm{HCHO}$ ), which are themselves precursors for $\mathrm{HO}_{\mathrm{x}}$ (Simpson et al., 2007b). The production of $\mathrm{HONO}$ and $\mathrm{NO}_{\mathrm{x}}$ via the photolysis of a nitrate impurity in the snow could also play an important role in perturbing the $\mathrm{HO}_{\mathrm{x}}$ budget. A few other possibilities for $\mathrm{HO}_{\mathrm{x}}$ formation, including the photodissociation of surface adsorbed $\mathrm{O}_{3}$ or reactions involving thermally-hot $\mathrm{O}\left({ }^{3} \mathrm{P}\right)$, are considered in the Supplement.

Figure S1 in the Supplement shows that reducing the ozone concentrations leads to an overall decrease in the halogen production. Figure $\mathrm{S} 2$ shows that the evolution of the dihalogen fractions with time is independent of gas phase $\left[\mathrm{O}_{3}\right]$ over this range, suggesting that the chemical mechanism is not affected by changing the ozone concentrations over the range.

\subsection{Brine chemistry}

An important question concerns the environment where the chemistry is occurring. When salt solutions freeze, salt ions are excluded from the growing ice matrix into an increasingly concentrated liquid brine. Thus, it has been well-established that sodium halide solutions will contain small liquid fractions down to temperatures at, or even slightly below, their eutectic temperatures (Koop et al., 2000). Together, the tem- perature and salt concentration dependence that we observe suggests that the photochemical halogen production takes place in such a concentrated liquid brine located at the surface of the snow grains. The reasons for this are as follows. At temperatures near or below the $\mathrm{NaCl}$-water eutectic of $252 \mathrm{~K}$ (Koop et al., 2000), the brine fraction is negligible. Under these conditions, illustrated in Fig. 3f, we find dihalogen production to be significantly suppressed, indicating that chloride availability in a liquid brine is key to this mechanism. At temperatures below the eutectic, chloride will be precipitated in any remaining brine, leading to chemical fractionation. We observe that the $\mathrm{Cl}_{2}$ fraction grows more slowly at colder temperatures (see Fig. S3a in the Supplement), indicating that the bromide/chloride ratio in the existing brine may be affected by the removal of chloride via precipitation. Fractionation of bromide with respect to chloride has previously been shown to affect heterogeneous chemistry on frozen halide surfaces (Lopez-Hilfiker et al., 2012). Huff and Abbatt (2000) have reported the only laboratory study of $\mathrm{HOCl}$ interactions with halide-containing ice surfaces. They also report no reaction for $\mathrm{HOCl}$ or $\mathrm{Cl}_{2}$ with frozen $\mathrm{NaCl}(\mathrm{aq})$ ice films at temperatures below the $\mathrm{NaCl}$-water eutectic.

The influence of temperature on the $\mathrm{Cl}_{2}$ production is further illustrated in Fig. 5, which shows the total $\mathrm{Cl}_{2}$ yield in 50 minutes of illumination as a function of snow sample temperature. The yields were calculated by integrating the $\mathrm{Cl}_{2}$ concentration-time signal to 50 minutes and scaling by the flow rate. Interestingly, the $\mathrm{Cl}_{2}$ yields are independent of temperature above the eutectic. Thermodynamic models for calculating brine concentrations (Cho et al., 2002; Kuo et al., 2011) predict that the brine halide concentrations are a strong function of temperature. Thus, the temperature independence we observe suggests that $\mathrm{Cl}_{2}$ production is independent of brine $\left[\mathrm{Cl}^{-}\right]$(which is quite high in the brine due to this temperature-dependent freeze-concentration). This observation is consistent with initial protonation of $\mathrm{HOCl}$ being rate-limiting, as discussed in Sect. 3.6, although given its complexity, the exact mechanism cannot be confirmed.

Changing the pre-freezing $[\mathrm{NaCl}]$ concentration was found to have an effect on the total dihalogen concentrations (Fig. S4 in the Supplement) but no effect on the time evolution of the dihalogen fractions (Fig. S5 in the Supplement) over the range $0.1-1.0 \mathrm{M}$. This likely indicates that (a) fractionation of the halides does not occur during freezing and the $\mathrm{Br}^{-} / \mathrm{Cl}^{-}$ratio in the brine is the same for the three concentrations studied; (b) the chemical mechanism remains the same in all three cases; and (c) the difference in the absolute dihalogen production is due to differences in the total halide content (i.e. brine fraction).

\section{Conclusions}

We have observed accelerated halogen activation, in particular $\mathrm{Cl}_{2}$ activation, from artificial saline snow in the presence 


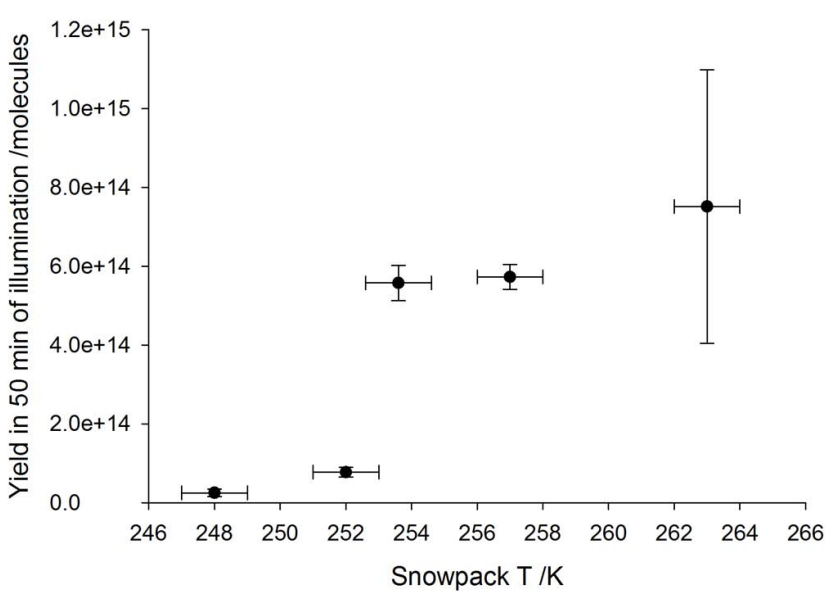

Fig. 5. Dependence of the chlorine $\left(\mathrm{Cl}_{2}\right)$ yield as a function of snowpack T. Vertical error bars represent the range from two trials. Horizontal error bars represent the estimated uncertainty in the snowpack $\mathrm{T}$. The yields were calculated by integrating the $\mathrm{Cl}_{2}$ concentration-time signal to $50 \mathrm{~min}$ and scaling by the flow rate.

of ozone and radiation of actinic wavelengths. Illumination of the snow samples was found to lead to the rapid release of $\mathrm{Br}_{2}$, then $\mathrm{BrCl}$, and ultimately the release of $\mathrm{Cl}_{2}$. Our observations are consistent with chemistry occurring in a concentrated liquid brine located at the surface of the snow grains, with chlorine activation only occurring at temperatures above the eutectic $(252 \mathrm{~K})$. We found the production of the dihalogens to be favoured under acidic conditions, more so for $\mathrm{Cl}_{2}$ than for $\mathrm{Br}_{2}$. Finally our results show that photochemical halogen activation, particularly chlorine activation, is enhanced when a larger surface area is present. Provided a $\mathrm{HO}_{\mathrm{x}}$ source is present, the results are most consistent with a 'halogen explosion' mechanism in which $\mathrm{HOBr}$ and $\mathrm{HOCl}$ are formed via the gas phase reaction of $\mathrm{O}_{3}$ by halogen radicals and are recycled back into the snow to oxidize $\mathrm{Br}^{-}$or $\mathrm{Cl}^{-}$.

\subsection{Atmospheric implications}

Considerable debate has centred on where bromine activation occurs in the polar regions, with proposals that first-year sea ice (Simpson et al., 2007a); frost flowers (Rankin et al., 2002; Kaleschke et al., 2004); saline snowpack (Morin et al., 2008) and blowing salty snow (Yang et al., 2010; Jones et al., 2009) play an important role. These substrates have variously been proposed for their high salinity, large surface area or enriched bromide content.

Given the strong acidity and surface area requirement we observe for chlorine production, we propose that aged saline snow (i.e. at a coastal location) will be most important for chlorine activation in the polar boundary layer. Although the $\mathrm{pH}$ at the air-ice interface has not been well-constrained, the bulk $\mathrm{pH}$ of seawater and seawater-derived substrates (frost flowers, first-year sea ice, brines) is alkaline ( $\mathrm{pH} \sim 8.3$ ) and is buffered against $\mathrm{pH}$ change by the carbonate system. Furthermore, work from our group suggests that the $\mathrm{pH}$ at an air-ice interface is largely unchanged during freezing (Wren and Donaldson, 2012a) and that the frozen seawater surface maintains some buffering capacity (Wren and Donaldson, 2012b). Snowpacks at coastal locations can achieve much lower $\mathrm{pH}$ values $(\sim 4.5)$ if they are aged (i.e. have been acidified by atmospheric trace acids) (Jacobi et al., 2012; de Caritat et al., 2005). The $\mathrm{pH}$ of snow at inland sites may be even lower, but these samples may also be limited in their halide content. Acidification of natural snow samples may also lead to a very low local surface $\mathrm{pH}$ which is not captured by the bulk, melted $\mathrm{pH}$. The relatively low surface areas of first-year sea ice and even frost flowers (Domine et al., 2005; Obbard et al., 2009) also preclude them from playing an important role in activating chlorine via the process observed in this study. In our study, we provide strong evidence for active chemistry occurring within the interstitial air of snow that is enhanced when a larger surface area is present. The proposal that aged, acidic snow is most relevant to halogen activation is consistent with very recent measurements by Pratt et al. (2013) showing efficient bromine release from natural snow samples but not from sea ice or brine icicles.

Halide concentrations in coastal snowpacks can vary widely, with average chloride concentrations ranging from $<1000->33000 \mu \mathrm{g} \mathrm{L}^{-1}$ and average bromide concentrations ranging from $30-450 \mu \mathrm{g} \mathrm{L}^{-1}$ for snow over first-year ice (and lower for snow on land or multi-year ice) (Jacobi et al., 2012; Krnavek et al., 2012). However, due to freezeconcentration effects, the concentration of halides available at the surface of real snow grains may be quite high, and, assuming thermodynamic models correctly treat such systems, should be a function of temperature rather that total salinity (Kuo et al., 2011; Cho et al., 2002). Furthermore, snow metamorphism may help mobilize the halides within the snowpack (whereas our artificial snow may contain trapped liquid pockets due to the very harsh freezing conditions).

Observation of both $\mathrm{Br}^{-}$-enriched and $\mathrm{Br}^{-}$-depleted snow have been observed in the field, with enrichments attributed to non-sea salt contribution from $\mathrm{HOBr}$ and depletions due to bromine activation chemistry (Jacobi et al., 2012; $\mathrm{Kr}$ navek et al., 2012). The dependence on the $\mathrm{Br}^{-} / \mathrm{Cl}^{-}$ratio we observe is quite interesting. On the one hand, when a large amount of bromide is available, it will preferentially be oxidized over chloride, and so production of $\mathrm{Br}_{2}$ and $\mathrm{BrCl}$ should dominate. High bromide concentrations will also react at the surface with $\mathrm{Cl}_{2}$ and $\mathrm{BrCl}$ to form $\mathrm{BrCl}$ or $\mathrm{Br}_{2}$ respectively, as has been observed by laboratory experiments (Huff and Abbatt, 2000; Adams et al., 2002; Huff and Abbatt, 2002). However, our experiments do suggest that molecular $\mathrm{Cl}_{2}$ is formed even when bromide is still present. On the other hand, we find that chlorine production decreases when the bromide/chloride decreases, which implies the involvement of $\mathrm{HOBr}$ formed via prior bromine activation. Thus, a certain amount of bromide may be necessary to initiate this 
chemistry. The photochemical halogen activation we observe is very efficient and should lead to rapid depletion of snow bromide. The high surface area of snow, together with bromide's strong surface affinity (Jungwirth and Tobias, 2006) should particularly favour rapid depletion of snow bromide.

An important question concerns the role that $\mathrm{BrCl}$ plays in contributing to the $\mathrm{Cl}$ radical budget and to further chlorine activation. Our results show that a process involving light and ozone could liberate large amounts of $\mathrm{BrCl}$ from aged, surface snow, which will release $\mathrm{Cl}$ radicals upon photolysis. $\mathrm{BrCl}$ is important here, not only as a direct $\mathrm{Cl}$ radical source, but as a precursor to $\mathrm{HOCl}$ formation, which we suggest leads to $\mathrm{Cl}_{2}$ formation. Generally consistent with our study, observations of $\mathrm{Br}_{2}$ and $\mathrm{BrCl}$ over snow at Alert show similar trends for both dihalogens, with $\mathrm{Br}_{2}$ reaching as high as $25 \mathrm{ppt}$ and $\mathrm{BrCl}$ reaching as high as $35 \mathrm{ppt}$ (Foster et al., 2001; Spicer et al., 2002). Notably, BrCl was not observed above the 2 ppt detection limit at the beginning of the campaign (in total darkness) but was observed almost continuously midway through the campaign and onwards; $\mathrm{Cl}_{2}$ was not observed above the 2 ppt detection limit. The later appearance of $\mathrm{BrCl}$ may be related to both bromide depletion in the snow and the increasing irradiance during the campaign.

Our results implicate the need for a "seed" reactive halogen source as well as a sustained $\mathrm{HO}_{\mathrm{x}}$ source within the snow. Although the relatively high ozone concentrations were likely responsible for the formation of "seed" $\mathrm{Br}_{2}$ and $\mathrm{BrCl}$ in this study, $\mathrm{OH}$ produced within natural snowpacks may play an important role in the initial formation of these species in the field (Pratt et al., 2013). This indicates that nitrate snowpack photochemistry and organic release from the snow - both of which affect the $\mathrm{HO}_{\mathrm{x}}$ budget - are likely intimately linked to halogen activation; further research is required to improve our understanding of the highly coupled air-ice interactions occurring within the snowpack.

The polar regions, and particularly the Arctic, are strongly affected by our changing climate. In the Arctic, a large decrease in sea ice extent has been accompanied by an increase in the relative area of first-year sea ice compared to multiyear ice (Maslanik et al., 2007). A long-term increase in the frequency of ozone depletion events during early spring may be attributed to this change (Oltmans et al., 2012). Given that snow lying on first-year sea ice has a higher salinity, halogen chemistry is expected to be affected as the Arctic succumbs to further changes. Our study contributes significantly to our growing understanding of halogen activation processes and how they might be impacted in a changing world. Further research is required using authentic snow and ice substrates to support the work presented here.

\section{Supplementary material related to this article is available online at http://www.atmos-chem-phys.net/13/ 9789/2013/acp-13-9789-2013-supplement.pdf.}

Acknowledgements. This work was funded by NSERC. SNW thanks NSERC for a PGS-D scholarship. Thanks are also extended to Greg Wentworth and Philip Gregoire for their help with the IC analysis of the snow samples.

Edited by: D. J. Cziczo

\section{References}

Abbatt, J., Oldridge, N., Symington, A., Chukalovskiy, V., McWhinney, R. D., Sjostedt, S., and Cox, R. A.: Release of Gas-Phase Halogens by Photolytic Generation of $\mathrm{OH}$ in Frozen Halide-Nitrate Solutions: An Active Halogen Formation Mechanism?, J. Phys. Chem. A, 114, 6527-6533, 2010.

Abbatt, J. P. D., Thomas, J. L., Abrahamsson, K., Boxe, C., Granfors, A., Jones, A. E., King, M. D., Saiz-Lopez, A., Shepson, P. B., Sodeau, J., Toohey, D. W., Toubin, C., von Glasow, R., Wren, S. N., and Yang, X.: Halogen activation via interactions with environmental ice and snow in the polar lower troposphere and other regions, Atmos. Chem. Phys., 12, 6237-6271, doi:10.5194/acp-12-6237-2012, 2012.

Adams, J. W., Holmes, N. S., and Crowley, J. N.: Uptake and reaction of $\mathrm{HOBr}$ on frozen and dry $\mathrm{NaCl} / \mathrm{NaBr}$ surfaces between 253 and 233 K, Atmos. Chem. Phys., 2, 79-91, 2002, http://www.atmos-chem-phys.net/2/79/2002/.

Cho, H., Shepson, P. B., Barrie, L. A., Cowin, J. P., and Zaveri, R.: NMR investigation of the quasi-brine layer in ice/brine mixtures, J. Phys. Chem. B., 106, 11226-11232, 2002.

de Caritat, P., Hall, G., Gislason, S., Belsey, W., Braun, M., Goloubeva, N. I., Olsen, H. K., Scheie, J. O., and Vaive, J. E.: Chemical composition of arctic snow: concentration levels and regional distribution of major elements, Sci. Total Environ., 336, 183-199, 2005.

Domine, F. and Shepson, P. B.: Air-snow interactions and atmospheric chemistry, Science, 297, 1506-1510, 2002.

Domine, F., Taillandier, A. S., Simpson, W. R., and Severin, K.: Specific surface area, density and microstructure of frost flowers, Geophys. Res. Lett., 32, L13502, doi:10.1029/2005GL023245, 2005.

Donaldson, D. J., Ravishankara, A. R., Hanson, D. R.: Detailed Study of $\mathrm{HOCl}+\mathrm{HCl} \rightarrow \mathrm{Cl}_{2}+\mathrm{H}_{2} \mathrm{O}$ in Sulfuric Acid, J. Phys. Chem. A., 101, 4717-4725, 1997.

Fan, S. M. and Jacob, D. J.: Surface ozone depletion in arctic spring sustained by bromine reactions on aerosols, Nature, 359, 522524, 1992.

Fickert, S., Adams, J. W., and Crowley, J. N.: Activation of $\mathrm{Br}_{2}$ and $\mathrm{BrCl}$ via uptake of $\mathrm{HOBr}$ onto aqueous salt solutions, J. Geophys. Res. Atmos., 104, 23719-23727, 1999.

Finlayson-Pitts, B. J.: The tropospheric chemistry of sea salt: A molecular-level view of the chemistry of $\mathrm{NaCl}$ and $\mathrm{NaBr}$, Chem. Rev., 103, 4801-4822, 2003.

Finlayson-Pitts, B. J., Pitts, J., and James N.: Chemistry of the Upper and Lower Atmosphere, Academic Press, USA, p. 114, 2000.

Foster, K. L., Plastridge, R. A., Bottenheim, J. W., Shepson, P. B., Finlayson-Pitts, B. J., and Spicer, C. W.: The role of $\mathrm{Br}_{2}$ and $\mathrm{BrCl}$ in surface ozone destruction at polar sunrise, Science, 291, 471-474, 2001.

Gao, S. S. and Abbatt, J. P. D.: Kinetics and mechanism of oh oxidation of small organic dicarboxylic acids in ice: comparison to 
behavior in aqueous solution, J. Phys. Chem. A, 115, 9977-9986, 2011.

Gao, S. S., Sjostedt, S. J., Sharma, S., Hall, S. R., Ullmann, K., and Abbatt, J. P. D.: PTR-MS observations of photo-enhanced VOC release from Arctic and midlatitude snow, J. Geophys. Res. Atmos., 117, D00R17, doi:10.1029/2011JD017152, 2012.

Grannas, A. M., Jones, A. E., Dibb, J., Ammann, M., Anastasio, C., Beine, H. J., Bergin, M., Bottenheim, J., Boxe, C. S., Carver, G., Chen, G., Crawford, J. H., Domine, F., Frey, M. M., Guzman, M. I., Heard, D. E., Helmig, D., Hoffmann, M. R., Honrath, R. E., Huey, L. G., Hutterli, M., Jacobi, H. W., Klan, P., Lefer, B., McConnell, J., Plane, J., Sander, R., Savarino, J., Shepson, P. B., Simpson, W. R., Sodeau, J. R., von Glasow, R., Weller, R., Wolff, E. W., and Zhu, T.: An overview of snow photochemistry: evidence, mechanisms and impacts, Atmos. Chem. Phys., 7, 43294373, doi:10.5194/acp-7-4329-2007, 2007.

Huey, L. G., Hanson, D. R., and Howard, C. J.: Reactions of $\mathrm{SF}_{6}^{-}$ and $\mathrm{I}^{-}$with atmospheric trace gases, J. Phys. Chem., 99, 50015008, 1995.

Huff, A. K. and Abbatt, J. P. D.: Gas-phase $\mathrm{Br}_{2}$ production in heterogeneous reactions of $\mathrm{Cl}_{2}, \mathrm{HOCl}$, and $\mathrm{BrCl}$ with halide-ice surfaces, J. Phys. Chem. A, 104, 7284-7293, 2000.

Huff, A. K. and Abbatt, J. P. D.: Kinetics and product yields in the heterogeneous reactions of $\mathrm{HOBr}$ with ice surfaces containing $\mathrm{NaBr}$ and $\mathrm{NaCl}$, J. Phys. Chem. A, 106, 5279-5287, 2002.

Impey, G. A., Shepson, P. B., Hastie, D. R., Barrie, L. A., and Anlauf, K. G.: Measurements of photolyzable chlorine and bromine during the Polar sunrise experiment 1995, J. Geophys. Res. Atmos., 102, 16005-16010, 1997.

Jacobi, H. W., Voisin, D., Jaffrezo, J. L., Cozic, J., and Douglas, T. A.: Chemical composition of the snowpack during the OASIS spring campaign 2009 at Barrow, Alaska, J. Geophys. Res. Atmos., 117, D00R13, doi:10.1029/2011JD016654, 2012.

Jones, A. E., Anderson, P. S., Begoin, M., Brough, N., Hutterli, M. A., Marshall, G. J., Richter, A., Roscoe, H. K., and Wolff, E. W.: $\mathrm{BrO}$, blizzards, and drivers of polar tropospheric ozone depletion events, Atmos. Chem. Phys., 9, 4639-4652, doi:10.5194/acp-94639-2009, 2009.

Jungwirth, P. and Tobias, D. J.: Specific ion effects at the air/water interface, Chem. Rev., 106, 1259-1281, 2006.

Kaleschke, L., Richter, A., Burrows, J., Afe, O., Heygster, G., Notholt, J., Rankin, A. M., Roscoe, H. K., Hollwedel, J., Wagner, T., and Jacobi, H. W.: Frost flowers on sea ice as a source of sea salt and their influence on tropospheric halogen chemistry, Geophys. Res. Lett., 31, L16114, doi:10.1029/2004GL020655, 2004.

Kirchner, U., Benter, T., and Schindler, R. N.: Experimental verification of gas phase bromine enrichment in reactions of $\mathrm{HOBr}$ with sea salt doped ice surfaces, Phys. Chem. Chem. Phys., 101, 975-977, 1997.

Knipping, E. M., Lakin, M. J., Foster, K. L., Jungwirth, P., Tobias, D. J., Gerber, R. B., Dabdub, D., and Finlayson-Pitts, B. J.: Experiments and simulations of ion-enhanced interfacial chemistry on aqueous $\mathrm{NaCl}$ aerosols, Science, 288, 301-306, 2000.

Koop, T., Kapilashrami, A., Molina, L. T., and Molina, M. J.: Phase transitions of sea-salt/water mixtures at low temperatures: Implications for ozone chemistry in the polar marine boundary layer, J. Geophys. Res. Atmos., 105, 26393-26402, 2000.
Krnavek, L., Simpson, W. R., Carlson, D., Domine, F., Douglas, T. A., and Sturm, M.: The chemical composition of surface snow in the Arctic: Examining marine, terrestrial, and atmospheric influences, Atmos. Environ., 50, 349-359, 2012.

Kuo, M. H., Moussa, S. G., and McNeill, V. F.: Modeling interfacial liquid layers on environmental ice, Atmos. Chem. Phys., 11, 9971-9982, doi:10.5194/acp-11-9971-2011, 2011.

Liao, J., Huey, L. G., Liu, Z., Tanner, D. J., Cantrell, C. A., Orlando, J. J., Flocke, F. M., Shepson, P. B., Weinheimer, A. J., Hall, S. R., Beine, H. J. B., Wang, Y., Ingall, E. D., Stephens, C. R. S., Hornbrook, R. S. H., Apel, E., Fried, A. F., Mauldin, L. M., Smith, J. N., Staebler, R. M. S., Neuman, J. A., and Nowak, J. B. N.: Observations of very high levels of molecular chlorine at Barrow, AK, Nature Geoscience, submitted, 2013.

Lopez-Hilfiker, F. D., Constantin, K., Kercher, J. P., and Thornton, J. A.: Temperature dependent halogen activation by $\mathrm{N}_{2} \mathrm{O}_{5}$ reactions on halide-doped ice surfaces, Atmos. Chem. Phys., 12, 5237-5247, doi:10.5194/acp-12-5237-2012, 2012.

Maslanik, J. A., Fowler, C., Stroeve, J., Drobot, S., Zwally, J., Yi, D., and Emery, W.: A younger, thinner Arctic ice cover: Increased potential for rapid, extensive sea-ice loss, Geophys. Res. Lett., 34, 5, L24051 doi:10.1029/2007g1032043, 2007.

Morin, S., Marion, G. M., von Glasow, R., Voisin, D., Bouchez, J., and Savarino, J.: Precipitation of salts in freezing seawater and ozone depletion events: a status report, Atmos. Chem. Phys., 8, 7317-7324, doi:10.5194/acp-8-7317-2008, 2008.

Obbard, R. W., Roscoe, H. K., Wolff, E. W., and Atkinson, H. M.: Frost flower surface area and chemistry as a function of salinity and temperature, J. Geophys. Res. Atmos., 114, D20305, doi:10.1029/2009jd012481, 2009.

Oldridge, N. W. and Abbatt, J. P. D.: Formation of Gas-Phase Bromine from Interaction of Ozone with Frozen and Liquid $\mathrm{NaCl} / \mathrm{NaBr}$ Solutions: Quantitative Separation of Surficial Chemistry from Bulk-Phase Reaction, J. Phys. Chem. A, 115, 2590-2598, 2011.

Oltmans, S. J., Johnson, B. J., and Harris, J. M.: Springtime boundary layer ozone depletion at Barrow, Alaska: Meteorological influence, year-to-year variation, and long-term change, J. Geophys. Res. Atmos., 117, D00R18, doi:10.1029/2011JD016889, 2012.

Oum, K. W., Lakin, M. J., and Finlayson-Pitts, B. J.: Bromine activation in the troposphere by the dark reaction of $\mathrm{O}_{3}$ with seawater ice, Geophys. Res. Lett., 25, 3923-3926, 1998.

Pratt, K. A., Custard, K. D., Shepson, P. B., Thomas, D. A., Pohler, D., General, S., Zielcke, J., Simpson, W. R., Platt, U., Tanner, D. J., Huey, L. G., Carlson, M., and Stirm, B. H.: Photochemical Production of Molecular Bromine in Arctic Surface Snowpacks, Nature Geosci., 6, 351-356, 2013.

Rankin, A. M., Wolff, E. W., and Martin, S.: Frost flowers: Implications for tropospheric chemistry and ice core interpretation, J. Geophys. Res. Atmos., 107, 4683, doi:10.1029/2002JD002492, 2002.

Saiz-Lopez, A. and von Glasow, R.: Reactive halogen chemistry in the troposphere, Chem. Soc. Rev., 41, 6448-6472, 2012.

Simpson, W. R., Carlson, D., Honninger, G., Douglas, T. A., Sturm, M., Perovich, D., and Platt, U.: First-year sea-ice contact predicts bromine monoxide $(\mathrm{BrO})$ levels at Barrow, Alaska better than potential frost flower contact, Atmos. Chem. Phys., 7, 621-627, doi:10.5194/acp-7-621-2007, 2007a. 
Simpson, W. R., von Glasow, R., Riedel, K., Anderson, P., Ariya, P., Bottenheim, J., Burrows, J., Carpenter, L. J., Friess, U., Goodsite, M. E., Heard, D., Hutterli, M., Jacobi, H. W., Kaleschke, L., Neff, B., Plane, J., Platt, U., Richter, A., Roscoe, H., Sander, R., Shepson, P., Sodeau, J., Steffen, A., Wagner, T., and Wolff, E.: Halogens and their role in polar boundary-layer ozone depletion, Atmos. Chem. Phys., 7, 4375-4418, doi:10.5194/acp-74375-2007, 2007b.

Sjostedt, S. J. and Abbatt, J. P. D.: Release of gas-phase halogens from sodium halide substrates: heterogeneous oxidation of frozen solutions and desiccated salts by hydroxyl radicals, Environ. Res. Lett, 3, 045007, doi:10.1088/1748-9326/3/4/045007, 2008.

Spicer, C. W., Plastridge, R. A., Foster, K. L., Finlayson-Pitts, B. J., Bottenheim, J. W., Grannas, A. M., and Shepson, P. B.: Molecular halogens before and during ozone depletion events in the Arctic at polar sunrise: concentrations and sources, Atmos. Environ., 36, 2721-2731, 2002.

Steffen, A., Douglas, T., Amyot, M., Ariya, P., Aspmo, K., Berg, T., Bottenheim, J., Brooks, S., Cobbett, F., Dastoor, A., Dommergue, A., Ebinghaus, R., Ferrari, C., Gardfeldt, K., Goodsite, M. E., Lean, D., Poulain, A. J., Scherz, C., Skov, H., Sommar, J., and Temme, C.: A synthesis of atmospheric mercury depletion event chemistry in the atmosphere and snow, Atmos. Chem. Phys., 8, 1445-1482, doi:10.5194/acp-8-1445-2008, 2008.

Stephens, C. R., Shepson, P. B., Steffen, A., Bottenheim, J. W., Liao, J., Huey, L. G., Apel, E., Weinheimer, A., Hall, S. R., Cantrell, C., Sive, B. C., Knapp, D. J., Montzka, D. D., and Hornbrook, R. S.: The relative importance of chlorine and bromine radicals in the oxidation of atmospheric mercury at Barrow, Alaska, J. Geophys. Res. Atmos., 117, D00R11, doi:10.1029/2011JD016649, 2012.
Tang, T. and McConnell, J. C.: Autocatalytic release of bromine from Arctic snow pack during polar sunrise, Geophys. Res. Lett., 23, 2633-2636, 1996.

Thornberry, T. and Abbatt, J. P. D.: Heterogeneous reaction of ozone with liquid unsaturated fatty acids: detailed kinetics and gasphase product studies, Phys. Chem. Chem. Phys., 6, 84-93, 2004.

Vogt, R., Crutzen, P. J., and Sander, R.: A mechanism for halogen release from sea-salt aerosol in the remote marine boundary layer, Nature, 383, 327-330, 1996.

Wren, S. N. and Donaldson, D. J.: Laboratory Study of pH at the Air-Ice Interface, J. Phys. Chem. C, 116, 10171-10180, 2012a.

Wren, S. N. and Donaldson, D. J.: How does deposition of gas phase species affect $\mathrm{pH}$ at frozen salty interfaces?, Atmos. Chem. Phys., 12, 10065-10073, doi:10.5194/acp-12-100652012, 2012 b.

Wren, S. N., Kahan, T. F., Jumaa, K. B., and Donaldson, D. J.: Spectroscopic studies of the heterogeneous reaction between $\mathrm{O}_{3}(\mathrm{~g})$ and halides at the surface of frozen salt solutions, J. Geophys. Res. Atmos., 115, D16309, doi:10.1029/2010jd013929, 2010.

Yang, X., Pyle, J. A., Cox, R. A., Theys, N., and Van Roozendael, M.: Snow-sourced bromine and its implications for polar tropospheric ozone, Atmos. Chem. Phys., 10, 7763-7773, doi:10.5194/acp-10-7763-2010, 2010. 